\title{
The identification of young people's emotional distress: a study in primary care
}

\author{
Dagmar M Haller, Lena A Sanci, Susan M Sawyer and George C Patton
}

\author{
ABSTRACT

\section{Background} \\ Primary care is a key step in young people's pathway \\ to mental health care. Despite the high prevalence of \\ mental disorder in this age group, little is known about \\ the factors that determine the identification of young \\ people's mental disorder in primary care. \\ Aim \\ To provide a detailed description of the factors \\ associated with both 'correct' and 'excessive' \\ identification of youth mental disorder in primary care. \\ Design of the study \\ Cross-sectional study. \\ Setting \\ Twenty-six randomly selected general practices in \\ Victoria, Australia.

\section{Method} \\ Consecutive young people (16-24 years) were \\ interviewed before their consultation, using a semi- \\ structured interview. They completed Kessler's scale of \\ emotional distress (K10). GPs completed a \\ questionnaire after the consultation. Multinomial logistic \\ regression was used to examine the factors associated \\ with GP identification of mental disorder in those with \\ high and low probability of disorder on the K10.

\section{Results} \\ Altogether, 450/501 (90\%) of approached young people \\ participated; $36.1 \%$ (95\% confidence interval $[\mathrm{Cl}]=$ \\ 32.3 to $40.2 \%$ ) had high probability of mental disorder \\ on the K10. Young people's perception that they had a \\ mental illness was highly associated with GP \\ identification (odds ratio $[\mathrm{OR}]=62.6,95 \% \mathrm{Cl}=22.8$ to \\ 172.0). Other significantly associated factors were: \\ patient fears $(\mathrm{OR}=2.4,95 \% \mathrm{Cl}=1.1$ to 5.1$)$, frequent \\ consultations ( $\mathrm{OR}=3.0,95 \% \mathrm{Cl}=1.0$ to 8.4 ), days out \\ of role $(\mathrm{OR}=2.7,95 \% \mathrm{Cl}=1.2$ to 5.7$)$, and continuity \\ of care $(\mathrm{OR}=3.4,95 \% \mathrm{Cl}=1.6$ to 6.9$)$. The latter two \\ were also associated with 'over-identification' of young \\ people who had low probability of mental disorder. GP \\ characteristics were not associated with identification.

\section{Conclusion} \\ These findings provide guidance for GPs in their \\ clinical work and training. They should also inform the \\ further development of mental health literacy \\ programmes in the community.

\section{Keywords} \\ adolescent; beliefs; diagnosis; epidemiology; family \\ practice; mental disorders.
}

\section{INTRODUCTION}

Mental disorders are a major burden on the health of young people. ${ }^{1}$ Their severe impact is dramatically illustrated by the fact that most young people who complete suicide suffered mental distress. ${ }^{1-3}$ Despite increasing knowledge, most affected young people do not receive mental health care. ${ }^{4}$ In 1980, Goldberg and Huxley proposed a framework for describing the pathways to mental health care, ${ }^{5}$ which was subsequently confirmed by international evidence and remains relevant today. ${ }^{6,7}$ Identification of emotional distress in primary care stands out as a key step on the pathway towards accessing mental health treatment.

Most young people see a primary care physician at least once a year. ${ }^{8}$ Young people with mental disorders consult primary care physicians more often than any other health professional, ${ }^{9}$ and the prevalence of mental disorders among young people attending primary care is as high as $30-40 \% .^{4,10,11}$ Often, however, they do not access professional care

DM Haller, PhD, MD, academic GP, Department of Community Medicine and Primary Care, Geneva University Hospitals and University of Geneva, Switzerland, and honorary fellow, Department of General Practice, The University of Melbourne, Australia. LA Sanci, PhD, FRACGP, senior lecturer, Department of General Practice, The University of Melbourne, Australia. SM Sawyer, MD, FRACP, professor of adolescent health and director; GC Patton, MD, FRANZC, professor of adolescent health research, Centre for Adolescent Health, Murdoch Children's Research Institute at the Royal Children's Hospital, Melbourne, Australia.

Address for correspondence

Dr Dagmar M Haller, University of Geneva, Department of Community Medicine and Primary Care,

rue Micheli-du-Crest, 24, Geneva, 1203, Switzerland. E-mail: dagmar.haller-hester@hcuge.ch

Submitted: 31 July 2008; Editor's response: 19 September 2008; final acceptance: 4 November 2008 .

(C)British Journal of General Practice

This is the full-length article of an abridged version published in print. Cite this article as: Br J Gen Pract 2009; DOI: 10.3399/bjgp09X419510. 


\section{How this fits in}

Little is known about the factors that determine GP identification of young people's mental disorders. Yet identification in primary care is a key step in young people's pathways to care. This study provides the first detailed description of the factors associated with both 'correct' and 'excessive' identification of youth mental disorder in primary care. It will inform the development of interventions to improve young people's pathways to mental health care. specifically for their mental health problem, ${ }^{12}$ and only $20-40 \%$ of those affected are identified in primary care. ${ }^{4,13,14}$ Doctors appear to have greater difficulty identifying mental disorder in young patients than in other age groups. ${ }^{15}$

Medical training has been proposed as one approach to improve GPs' identification of young people's emotional distress, ${ }^{13,14,16}$ yet even highly trained GPs fail to recognise mental health problems in up to $50 \%$ of their young patients..$^{4,13,14}$ Exploring other modifiable factors affecting identification is therefore important.

To date, only two studies have examined factors associated with GPs' identification of emotional distress in young people. Severity of the disorder stood out as an important factor, ${ }^{17,18}$ along with the active exploration of psychological issues in the consultation, and adolescents' self-definition of having significant psychological difficulties. ${ }^{18}$ Both studies were small and involved young adolescents (13-16 years). Evidence about specific factors associated with the identification of emotional distress in young people between 16 and 24 years is lacking, despite the particularly high prevalence of mental disorder in this age group. ${ }^{1}$

Studies involving adults provide guidance about the potentially modifiable factors associated with the identification of common mental disorders in young people. These studies have shown a relationship with sociodemographic factors such as age (young and older people) and unemployment. ${ }^{19}$ Other patient factors include severity of the disorder, frequent consultations, and patients' presentation to the GP. $^{20-22}$ Conflicting results have emerged as to the role of patients' symptom attribution in the identification of mental disorders. ${ }^{23,24}$ Little, however, is known about the role of patients' views on their own symptoms and the identification of emotional distress. ${ }^{24}$ In the current climate favouring patientcentred care, the potential role of patients' perspectives on their current health problems needs further scrutiny. ${ }^{19,25}$ Whereas GPs' attitudes to depression do not seem to be associated with their ability to identify mental disorders, GP's interview style may be influential. ${ }^{19,26}$ Conflicting results have emerged as to the role of GP training in improving the identification of emotional distress. ${ }^{27-29}$

In this study, evidence is provided from a large representative sample of young people attending primary care on the modifiable factors associated with the identification of their emotional distress. This includes the role of patients' beliefs about the symptoms for which they sought consultation.

\section{METHOD}

\section{Design and participants}

A cross-sectional study was undertaken in a random sample of 26 general practices throughout the State of Victoria, Australia (area approximately that of Great Britain, population 5.2 million). Patient recruitment took place between July 2004 and April 2005. In each practice, consecutive patients aged 16-24 years were invited to consent to an interview before the consultation. Patients were considered sufficiently mature to consent to participation on their own. ${ }^{30}$ Exclusion criteria were any condition that could impair the ability to consent (for example, acute condition requiring immediate attention, intellectual disability, or language barrier).

\section{Instruments and procedure}

The semi-structured interview was based on a standardised tool to assess illness beliefs in primary care: the Short Explanatory Model Interview (SEMI). ${ }^{31}$ This is a set of open-ended questions to assess patients' views on the cause and the course of their health problem, and their expectations from health care. ${ }^{32}$ The qualitative answers are coded into categories that can be quantified for epidemiological purposes. Illness beliefs are assessed on five components: patients' views about the cause of their health problem, its timing, its pathophysiology, its severity, and their expectations from the consultation. The interview also included questions assessing consultation behaviour ('is this your usual doctor?') and a standardised questionnaire of healthcare use (CSSRI - Client Sociodemographic and Service Receipt Inventory).. ${ }^{33}$ Participants completed a self-administered questionnaire including sociodemographic questions and Kessler's scale of emotional distress (K10). ${ }^{34}$ This 10-item scale measures levels of emotional distress indicative of a depressive or anxiety disorder. Scores range from a minimum of 10 (symptoms occur 'none of the time') to a maximum of 50 .

GP identification of emotional distress was recorded directly after the consultation, using the 5 -item scale of the World Health Organization (WHO) international study of mental health in primary care. ${ }^{1}$ GPs were considered to have identified mental disorder if they declared the patient had a minor, 
moderate, or severe mental illness. The level of socioeconomic disadvantage in the area of each practice was determined using Socioeconomic Indexes for Areas (SEIFA).

The procedure was tested in a pilot study involving 56 participants and 12 GPs, resulting in minimal changes to the final protocol.

\section{Analysis}

A sample size of 300 was estimated to measure proportions of categorical variables within a small margin of error (6\%). To allow for increased variance in estimates due to recruiting participants in practices, the sample size was inflated by a factor of 1.48 (20 per practice). The inflation factor was based on an intra-class correlation of 0.025 derived from the pilot study and literature..$^{35}$

Data were entered into EpiData (version 3.1, The EpiData Association, Odense Denmark), and analysed with Stata (version 9.0, StataCorp LP, Texas, US). Data from the SEMI were analysed for themes and coded following the codebook. ${ }^{31}$ An inter-coder reliability study for this coding showed excellent $\kappa$ values $(0.87$ to 0.96$)$. A binary variable was created from $\mathrm{K} 10$ scores, to differentiate those with levels of emotional distress indicative of a high probability $(\geq 78 \%)$ of mental disorder. ${ }^{34}$ Using stratum-specific likelihood ratios and the Bayesian method proposed by Furukawa et al, the cut-off score for this variable was set at $20 .^{36}$ The positive predictive value for a score of 20 or above was $\geq 0.78$. The negative predictive value was 0.65 (score of 19) to 0.97 (score of 11).

Taking into account $\mathrm{K} 10$ categories and GP identification of a mental disorder, four categories of GP recognition of emotional distress were compiled for use as the main outcome variable in the analysis: (1) K10 mental disorder No, GP No; (2) K10 No, GP Yes; (3) K10 Yes, GP No; and (4) K10 Yes, GP Yes.

Multinomial logistic regression was used to examine the association between the outcome and each of the factors. Variables showing a significant univariate association $(P \leq 0.05)$ with the outcome were entered into multivariate models. The analyses were first run in relation to patient and GP sociodemographic characteristics, then adjusted for these confounders. A series of models were fitted introducing variables in a stepwise manner (GPrelated factors, patient-related factors, and then beliefs), adjusting for clustering within practices. Factors were omitted if the $P$-value for the adjusted odds ratio was above 0.05 . Intra-class correlation coefficients for key variables ranged from 0.0 to 0.008 . Potential interactions between confounders and exposure variables were explored, and the analyses adjusted accordingly.

\section{RESULTS}

\section{Responder characteristics}

One-hundred and six GPs (59\% males) in 26 practices participated (43\% of contacted practices). There were no differences in the size, location, or number of services to 16-24-year-old patients in participating practices compared to those who declined.

Five-hundred and thirty-nine young people entered the practices during recruitment times, 38 could not be approached (another participant was already being interviewed or inclusion would have unacceptably delayed the GP consultation), and 450/501 (34.0\% males) participated (3\% excluded, $6 \%$ declined). Their sociodemographic characteristics by sex are presented in Appendix 1.

\section{Outcome: GP identification of young people's emotional distress}

Data for this outcome were available for 445 participants ( $\mathrm{K} 10$ data were missing from three participants; assessment of emotional distress was missing from two GPs). Overall, 161 participants (36.1\%, 95\% confidence interval $[\mathrm{Cl}]=32.3$ to $40.2 \%$ ) had $\mathrm{K} 10$ scores indicating a high probability of mental disorder. The proportion of young people with this probability was higher among females $(42.9 \%, 95 \% \mathrm{Cl}=37.8$ to $47.9 \%)$ than males (23.5\%, $95 \% \mathrm{Cl}=16.9$ to $30.1 \%)$. The distribution of GPs' identification of patients' emotional distress in those with low and high scores on the $\mathrm{K} 10$ is presented in Table 1. Approximately half of those who had a high probability of mental disorder on the K10 were identified by GPs. One-quarter of those who were identified by GPs as having a mental illness had a low probability of mental disorder on the K10.

\section{Consultation characteristics}

Half of the participants $(50.4 \%, 95 \% \mathrm{Cl}=41.6$ to 59.3) were attending their usual practice. Most $(90 \%, 95 \% \mathrm{Cl}=84$ to $91 \%)$ had consulted this or another health professional in the past 6 months,

\begin{tabular}{|c|c|c|c|}
\hline & $\begin{array}{l}\text { Low } \\
\text { dis } \\
\text { (sc }\end{array}$ & $\begin{array}{l}\text { probability of mental } \\
\text { sorder on the K10 } \\
\text { core <20) }(n=284)\end{array}$ & $\begin{array}{l}\text { High probability of mental } \\
\text { disorder on the K10 } \\
\text { (score } \geq 20(n=161)\end{array}$ \\
\hline & $n$ & $\left(\% ; 95 \% \mathrm{Cl}^{\mathrm{a}}\right)$ & $n \quad\left(\% ; 95 \% \mathrm{Cl}^{a}\right)$ \\
\hline $\begin{array}{l}\text { GP does not identify a } \\
\text { mental illness }(n=339)\end{array}$ & 257 & (57.8; 53.7 to 61.8$)$ & 82 (18.4: 14.5 to 22.4$)$ \\
\hline $\begin{array}{l}\text { GP identifies a mental } \\
\text { illness }(n=106)\end{array}$ & 27 & $(6.1 ; 3.7$ to 8.4$)$ & $79(17.7 ; 13.2$ to 22.3$)$ \\
\hline
\end{tabular}

${ }^{a}$ Adjusted for clustering within practices. 
Table 2. Cross-sectional adjusted associations between explored factors and GPs' identification of young people's emotional distress, in young people with low and high scores on the K10. Only the factors that significantly contribute to the model are presented.

\begin{tabular}{|c|c|c|c|c|c|c|c|}
\hline \multirow[b]{2}{*}{ Factors } & \multicolumn{4}{|c|}{$\begin{array}{l}\text { GP identification discordant } \\
\text { with results on the K10 } \\
(\text { K10 score }<20)\end{array}$} & \multicolumn{3}{|c|}{$\begin{array}{l}\text { GP identification concordant } \\
\text { with results on the K10 } \\
\text { (K10 score } \geq 20)\end{array}$} \\
\hline & $n$ & $\mathrm{OR}^{\mathrm{a}}$ & $95 \% \mathrm{Cl}$ & $P$-value & $\mathrm{OR}^{\mathrm{a}}$ & $95 \% \mathrm{Cl}$ & $P$-value \\
\hline \multicolumn{8}{|l|}{ Beliefs } \\
\hline Fears about current illness & 193 & 0.9 & 0.4 to 2.2 & 0.86 & 2.4 & 1.1 to 5.1 & 0.02 \\
\hline Self-perceived mild to severe mental illness & 107 & 0.6 & 0.1 to 5.4 & 0.58 & 62.6 & 22.8 to 172 & $<0.001$ \\
\hline Causal explanation: natural world & 139 & 0.5 & 0.2 to 1.5 & 0.22 & 0.1 & 0.0 to 0.5 & 0.01 \\
\hline \multicolumn{8}{|l|}{ Other patient factors } \\
\hline Consultations in past 6 months $^{\mathrm{b}}:>7$ consultations & 108 & 1.5 & 0.3 to 8.6 & 0.62 & 3.0 & 1.0 to 8.4 & 0.04 \\
\hline Days off school/work in past 6 months & 175 & 3.2 & 1.1 to 9.4 & 0.03 & 2.7 & 1.2 to 5.7 & 0.01 \\
\hline Came to usual practice & 227 & 6.5 & 1.4 to 29.5 & 0.02 & 3.4 & 1.6 to 6.9 & 0.02 \\
\hline
\end{tabular}

${ }^{a}$ Reference category for all analyses: neither identified by GP nor having high level of emotional distress on the K10.

${ }^{b}$ Consultation with any health professional, not only this GP.

with $24.0 \%(95 \% \mathrm{Cl}=20.1$ to $27.9 \%)$ reporting more than seven consultations during that period; $38.9 \%(95 \% \mathrm{Cl}=33.9$ to $43.9 \%)$ had missed school or work for health reasons in the preceding 6 months. A further description of participants' consultation characteristics can be found

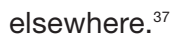

\section{Measures of association}

The factors associated with identification of mental disorder were modelled using multinomial logistic regression, the reference category being those with low scores on the $\mathrm{K} 10$ and no mental disorder according to the GP. The relationship between patient or GP sociodemographic confounders and the outcome is presented in Appendix 2. Table 2 presents the adjusted odds ratios (OR) for the association between selected factors and GP identification of emotional distress. More-detailed results are presented in Appendix 3.

\section{Sociodemographic confounders}

GP identification of mental disorder in those with high probability of mental disorder. Young people who were unemployed were more likely to be labelled as having a mental illness whether or not they had high scores on the K10. No other sociodemographic factors were associated with the 'correct' identification of mental disorder by GPs.

GP identification of mental disorder in young people with a low probability of mental disorder. Being a student or unemployed increased the odds of being identified as having a mental disorder, despite a low score on the K10.
Patients' illness beliefs, other patient factors, and GP/consultation factors

The following factors were not found to be associated with the outcome: young people's beliefs about the timing of their health problem, their expectations from the consultation, seeking advice from family/friends, coming to the practice on their own, GP level of training in mental health and adolescent health, and GP identification of a physical illness in the participant.

GP identification of those with a high probability of mental disorder. In the univariate models, several illness beliefs appeared related to the outcome. In the multivariate model, however, young people's self-perception of the severity of their mental health problem stood out as the predominant factor. Young people with high levels of emotional distress who perceived they had a minor to severe mental illness had sixfold higher odds of being correctly identified by GPs as compared to those who did not perceive they had a mental illness. Belief in a natural cause for the health problem was inversely associated with identification. There were slightly higher odds of identification in those who had fears in relation to their health problem. Continuity of care (attending usual practice), days out of role in the preceding 6 months, and more-frequent consultations were also associated with 'correct' identification.

GP identification of those with low probability of mental disorder. Participants who usually attended the practice and those who had days out of role in the preceding 6 months were more likely to be classified as having a mental illness despite having a low score on the K10. 


\section{DISCUSSION}

\section{Summary of main findings}

This is the first study to provide a detailed description of the factors associated with GPs' identification of emotional distress in young people aged 16-24 years. GPs typically identified mental disorder in those who perceived they had a mental illness and who expressed fears in relation to their health problem. Continuity of care and days out of role favoured identification, but also appeared to favour over-identification of those who were unlikely to have a mental disorder.

\section{Strengths and limitations of the study}

The inclusion of a large number of participants recruited from randomly selected practices throughout an entire state adds strength to the design and validity of the study findings. Causal inferences may not be drawn from these crosssectional data. The absence of detailed knowledge about the range of factors potentially associated with identification of mental disorder precluded the choice of a cohort design. The K10 is known to perform well in screening for mood and anxiety disorders. Other mental disorders may not have been identified using this instrument. However, mood and anxiety disorders are the most common mental health problems experienced by young people in this age group..$^{38,39}$ Other limitations include the potential bias related to coding participants' answers in the interview, but this was minimised by using clearly defined coding rules, as demonstrated by the high inter-coder agreement.

The analysis was able to identify both the factors related to the identification of emotional distress in patients with a high probability of mental disorder, and those associated with 'misclassification' of patients who had a low probability of mental disorder. Since the K10 is not a diagnostic tool, a score below 20 did not necessarily mean the young person did not have mental disorder, only that the probability that they had a disorder was low. ${ }^{11}$ Thus, GPs who identified emotional distress in these patients may not have provided an incorrect assessment.

\section{Comparison with existing literature}

This study's findings are consistent with those of a recent small study in which adolescents' perception of having significant psychological difficulties was associated with identification. ${ }^{18}$ As no direct observation of consultations took place, it is unknown to what extent the doctors were explicitly aware of their patients' perceptions. Young people's illness perceptions may have influenced their presentations to doctors, and therefore identification of their emotional distress. ${ }^{32}$
That patients who were familiar with the practice were more likely to be identified, whether they had elevated levels of emotional distress or not, suggests GPs are more likely to identify mental illness in patients they know. GPs may have based their assessment on knowledge of past mental illness in a patient, although the patient's current level of symptoms suggested remission from the disorder. Continuity of care favouring identification is also reported in adult studies and concords with reports that adolescents' prior experience of services provides them with the knowledge of how to present their symptoms in order to receive medical help. ${ }^{40,41}$ It has been argued that if continuous care is considered (rather than a cross-sectional view), only a minority of cases remain unidentified over time. ${ }^{38}$ In the present study, however, only half of the participants were coming to their usual practice. Discontinuous care could therefore be an important reason for the low recognition in primary care of young people's emotional distress.

Strikingly, none of the GP characteristics were related to the outcome. There was no association with GP age or sex, or with previous training in mental health or adolescent health. There is conflicting evidence about the association between GPs' level of training and the identification of youth emotional distress. ${ }^{13,14}$ In the present study, GPs' level of training was generally high. Whether medical education can improve GPs' identification of emotional distress in regions where the baseline level of training is low remains unanswered.

\section{Implications for future research or clinical practice}

These findings have implications for clinical practice, medical education, and health promotion. Young people have reported they frequently need guidance about when a mental health problem needs outside help, ${ }^{42}$ and are often unaware that GPs can offer such help. ${ }^{43}$ GPs can play a key role in offering guidance, by opportunistically enquiring about mental health symptoms, which can then be framed to young people as symptoms warranting help. Improved recognition in primary care would be expected if one could help young people acquire a better perception of the significance of their symptoms of emotional distress at a preclinical level. In turn, this could be expected to modify the way young people present to GPs and thus promote the identification of their emotional distress. ${ }^{32}$ Programmes that promote mental health literacy tend to favour recognition and acceptance of disease in others. ${ }^{44}$ The findings suggest a further emphasis should be placed on improving young people's ability to recognise symptoms in themselves. This would mean a shift 
from programmes centred on the development of skills to cope with stress and other social risk factors to programmes including the acquisition of skills to recognise and cope with emotional symptoms, whether overtly caused by stress or not, ${ }^{45}$ and to encourage them to seek assistance from GPs.

This study has uncovered the importance of young people's illness perceptions in the pathway to mental health care, and provides the grounds for future studies of this pathway to similarly include a measure of illness beliefs. It is hoped that by doing this, the understanding of how to improve pathways to recovery for young people affected by mental disorders is enhanced, in order to reduce the heavy burden caused by mental disorders on the health of young people. ${ }^{46}$

\section{Funding body}

This research was undertaken during a research fellowship for Dagmar M Haller, which was supported by Geneva University Hospitals and Academic Society, the Swiss National Science Foundation and an International Postgraduate Research Scholarship from The University of Melbourne. George C Patton is supported by an NH\&MRC senior principal research fellowship. None of these funding sources had any influence or control over the study, the decision to submit, or the preparation of the final manuscript for publication. All authors had full access to the data in the study and share the final responsibility for the decision to submit for publication

\section{Ethical approval}

The Ethics in Human Research Committee of the Royal Children's Hospital and the Ethical Committee of The University of Melbourne approved this protocol

\section{Competing interests}

The authors have stated that there are none

\section{Acknowledgements}

We wish to thank Carolyn Coffey for her precious help in analysing the data, and John Carlin and Jane Gunn for offering advice at different stages in the study. We also wish to thank the participating practices and patients for their valuable contribution to the study. We are grateful to Anthony Mann for his guidance in the initiation of the study, to Athula Sumathipala for making the SEMI available to us, and to Alec Hester for editorial advice.

\section{Discuss this article}

Contribute and read comments about this article on the Discussion Forum: http://www.rcgp.org.uk/bjgp-discuss

\section{REFERENCES}

1. Patel V, Flisher AJ, Hetrick S, McGorry P. Mental health of young people: a global public-health challenge. Lancet 2007; 369(9569): 1302-1313.

2. Patton GC, Viner R. Pubertal transitions in health. Lancet 2007; 369(9567): 1130-1139.

3. Gould MS, Greenberg T, Velting DM, Shaffer D. Youth suicide risk and preventive interventions: a review of the past 10 years. J Am Acad Child Adolesc Psychiatr 2003; 42(4): 386-405.

4. Hickie IB, Fogarty AS, Davenport TA, et al. Responding to experiences of young people with common mental health problems attending Australian general practice. Med J Aust 2007; 187(7 suppl): S47-52.

5. Goldberg D, Huxley P. Mental illness in the community: the pathway to psychiatric care. London: Tavistock, 1980.

6. Rickwood DJ, Deane FP, Wilson CJ. When and how do young people seek professional help for mental health problems? Med J Aust 2007; 187(7 suppl): S35-39.

7. Gater R, de Almeida e Sousa B, Barrientos G, et al. The pathways to psychiatric care: a cross-cultural study. Psychol Med 1991; 21(3):
761-774.

8. Tylee A, Haller DM, Graham T, et al. Youth-friendly primary-care services: how are we doing and what more needs to be done? Lancet 2007; 369(9572): 1565-1573.

9. Kramer T, Garralda ME. Child and adolescent mental health problems in primary care. Adv Psychiatr Treat 2000; 6(4): 287.

10. McKelvey RS, Pfaff JJ, Acres JG. The relationship between chief complaints, psychological distress, and suicidal ideation in 15-24year-old patients presenting to general practitioners. Med J Aust 2001; 175(10): 550-552.

11. Ustun TB, Sartorius N. Mental illness in general health care: an international study. Chichester: Wiley, 1995.

12. Sawyer MG, Arney FM, Baghurst PA, et al. The mental health of young people in Australia: key findings from the child and adolescent component of the national survey of mental health and well-being. Aust NZ J Psychiatry 2001; 35(6): 806-814.

13. Pfaff JJ, Acres JG, McKelvey RS. Training general practitioners to recognise and respond to psychological distress and suicidal ideation in young people. Med J Aust 2001; 174(5): 222-226.

14. Gledhill J, Kramer T, Iliffe S, Garralda ME. Training general practitioners in the identification and management of adolescent depression within the consultation: a feasibility study. J Adolesc 2003; 26(2): 245-250.

15. Raine R, Lewis L, Sensky T, et al. Patient determinants of mental health interventions in primary care. Br J Gen Pract 2000; 50(457): 620-625.

16. Sanci LA, Coffey CM, Veit FC, et al. Evaluation of the effectiveness of an educational intervention for general practitioners in adolescent health care: randomised controlled trial. BMJ 2000; 320(7229): 224-230.

17. Kramer T, Garralda ME. Psychiatric disorders in adolescents in primary care. Br J Psychiatry 1998; 173: 508-513.

18. Martinez R, Reynolds S, Howe A. Factors that influence the detection of psychological problems in adolescents attending general practices. Br J Gen Pract 2006; 56(529): 594-599.

19. Tylee A, Walters P, Maj M, et al. Early recognition and management of depression in primary care. Early detection and management of mental disorders. Chichester, West Sussex: John Wiley and Sons, 2005; 249-275.

20. The Mental Health and General Practice Investigation (MaGPIe) Research Group. General practitioner recognition of mental illness in the absence of a 'gold standard'. Aust NZ J Psychiatry 2004; 38(10): 789-794.

21. Bushnell J. Frequency of consultations and general practitioner recognition of psychological symptoms. Br J Gen Pract 2004; 54(508): 838-843.

22. Maginn S, Boardman AP, Craig TK, et al. The detection of psychological problems by general practitioners - influence of ethnicity and other demographic variables. Soc Psychiatry Psychiatr Epidemiol 2004; 39(6): 464-471.

23. Kessler D, Lloyd K, Lewis G, Gray DP. Cross sectional study of symptom attribution and recognition of depression and anxiety in primary care. BMJ 1999; 318(7181): 436-439.

24. Bower P, West R, Tylee A, Hann M. Symptom attribution and the recognition of psychiatric morbidity. J Psychosom Res 2000; 48(2): $157-160$.

25. Jacobson L, Churchill R, Donovan C, et al. Tackling teenage turmoil: primary care recognition and management of mental ill health during adolescence. Fam Pract 2002; 19(4): 401-409.

26. Dowrick C, Gask L, Perry R, et al. Do general practitioners' attitudes towards depression predict their clinical behaviour? Psychol Med 2000; 30(2): 413-419.

27. Rutz W, Walinder J, Eberhard G, et al. An educational program on depressive disorders for general practitioners on Gotland: background and evaluation. Acta Psychiatr Scand 1989; 79(1): 19-26.

28. Rutz W, von Knorring L, Walinder J. Long-term effects of an educational program for general practitioners given by the Swedish Committee for the Prevention and Treatment of Depression. Acta Psychiatr Scand 1992; 85(1): 83-88.

29. Thompson C, Kinmonth AL, Stevens L, et al. Effects of a clinicalpractice guideline and practice-based education on detection and outcome of depression in primary care: Hampshire Depression Project randomised controlled trial. Lancet 2000; 355(9199): 185-191.

30. Sanci LA, Sawyer SM, Weller PJ, et al. Youth health research ethics: time for a mature-minor clause? Med J Aust 2004; 180(7):336-338. 
31. Lloyd KR, Jacob KS, Patel V, et al. The development of the Short Explanatory Model Interview (SEMI) and its use among primarycare attenders with common mental disorders. Psychol Med 1998; 28(5): 1231-1237.

32. Kleinman A. Patients and healers in the context of culture. Berkeley: University of California Press, 1980.

33. Chisholm D, Knapp MRJ, Knudsen HC, et al. Client SocioDemographic and Service Receipt Inventory - European Version: development of an instrument for international research: EPSILON Study 5. Br J Psychiatry 2000; 177(39): s28-33.

34. Kessler RC, Andrews G, Colpe LJ, et al. Short screening scales to monitor population prevalences and trends in non-specific psychological distress. Psychol Med 2002; 32(6): 959-976.

35. Adams G, Gulliford MC, Ukoumunne OC, et al. Patterns of intracluster correlation from primary care research to inform study design and analysis. J Clin Epidemiol 2004; 57(8): 785-794.

36. Furukawa TA, Kessler RC, Slade T, Andrews G. The performance of the $\mathrm{K} 6$ and K10 screening scales for psychological distress in the Australian National Survey of Mental Health and Well-Being. Psychol Med 2003; 33(2):357-362.

37. Haller DM, Sanci LA, Patton GC, Sawyer SM. Toward youth friendly services: a survey of young people in primary care. J Gen Intern Med 2007; 22(6): 775-781.

38. The MaGPIe Research Group. The effectiveness of case-finding for mental health problems in primary care. Br J Gen Pract 2005; 55: 665-669.
39. Rogers A, May C, Oliver D. Experiencing depression, experiencing the depressed: the separate worlds of patients and doctors. J Ment Health 2005; 10(3): 317-333.

40. World Health Organization. The World Health Report 2001. Mental health: new understanding, new hope. Geneva: World Health Organization Publications, 2001.

41. Jenkins R, Lewis G, Bebbington P, et al. The National Psychiatric Morbidity Surveys of Great Britain - initial findings from the household survey. Int Rev Psychiatry 2003; 15(1-2): 29-42.

42. Keys Young. National Mental Health Strategy. Research and consultation among young people on mental health issues: final report. Canberra: Commonwealth Department of Health and Family, 1997.

43. Biddle L, Donovan JL, Gunnell D, Sharp D. Young adults' perception of GPs as a help source for mental distress: a qualitative study. $\mathrm{Br} J$ Gen Pract 2006; 56(533): 924-931.

44. Kelly CM, Jorm AF, Wright A. Improving mental health literacy as a strategy to facilitate early intervention for mental disorders. Med J Aust 2007; 187(7 suppl): S26-30.

45. Hamburg DA, Millstein SG, Mortimer AM, et al. Adolescent health promotion in the twenty-first century: current frontiers and future directions. Promoting the health of adolescents, new directions for the twenty-first century. New York: Oxford University Press; 1993. pp. 375-388.

46. Viner RM, Barker M. Young people's health: the need for action. BMJ 2005; 330(7496): 901-903. 
Appendix 1. Sociodemographic characteristics of study participants, by $\operatorname{sex}(n=450)$.

\begin{tabular}{lccccccc} 
Characteristic & \multicolumn{2}{c}{ Male $(n=153)$} & \multicolumn{2}{c}{ Female $(n=297)$} & \multicolumn{3}{c}{ Total $(n=450)$} \\
\hline & $n$ & Years & $n$ & Years & $n$ & Years & SD \\
\cline { 2 - 10 } Mean age, years & 153 & 19.6 & 297 & 20.1 & 450 & 20.0 & 2.5 \\
\hline \multirow{2}{*}{ Born overseas } & 22 & 14.4 & 49 & 16.5 & 71 & 15.8 & 7.9 to 23.7 \\
\hline Indigenous & 1 & 0.7 & 2 & 0.7 & 3 & 0.7 & 0 to 1.4 \\
\hline Student & 88 & 59.1 & 172 & 58.2 & 260 & 58.5 & 49.5 to 67.3 \\
\hline Employed full-time & 57 & 38.3 & 81 & 27.7 & 138 & 31.3 & 24.2 to 37.8 \\
\hline Neither employed nor student & 9 & 6 & 29 & 9.8 & 38 & 8.4 & 5.2 to 11.9 \\
\hline Healthcare card holder & 51 & 33 & 111 & 38 & 162 & 36.3 & 29.3 to 43.3 \\
\hline
\end{tabular}

$S D=$ standard deviation. 


\section{Appendix 2. Cross-sectional associations between young people's and GPs' demographic variables (confounders) and GP identification of young people's emotional distress.}

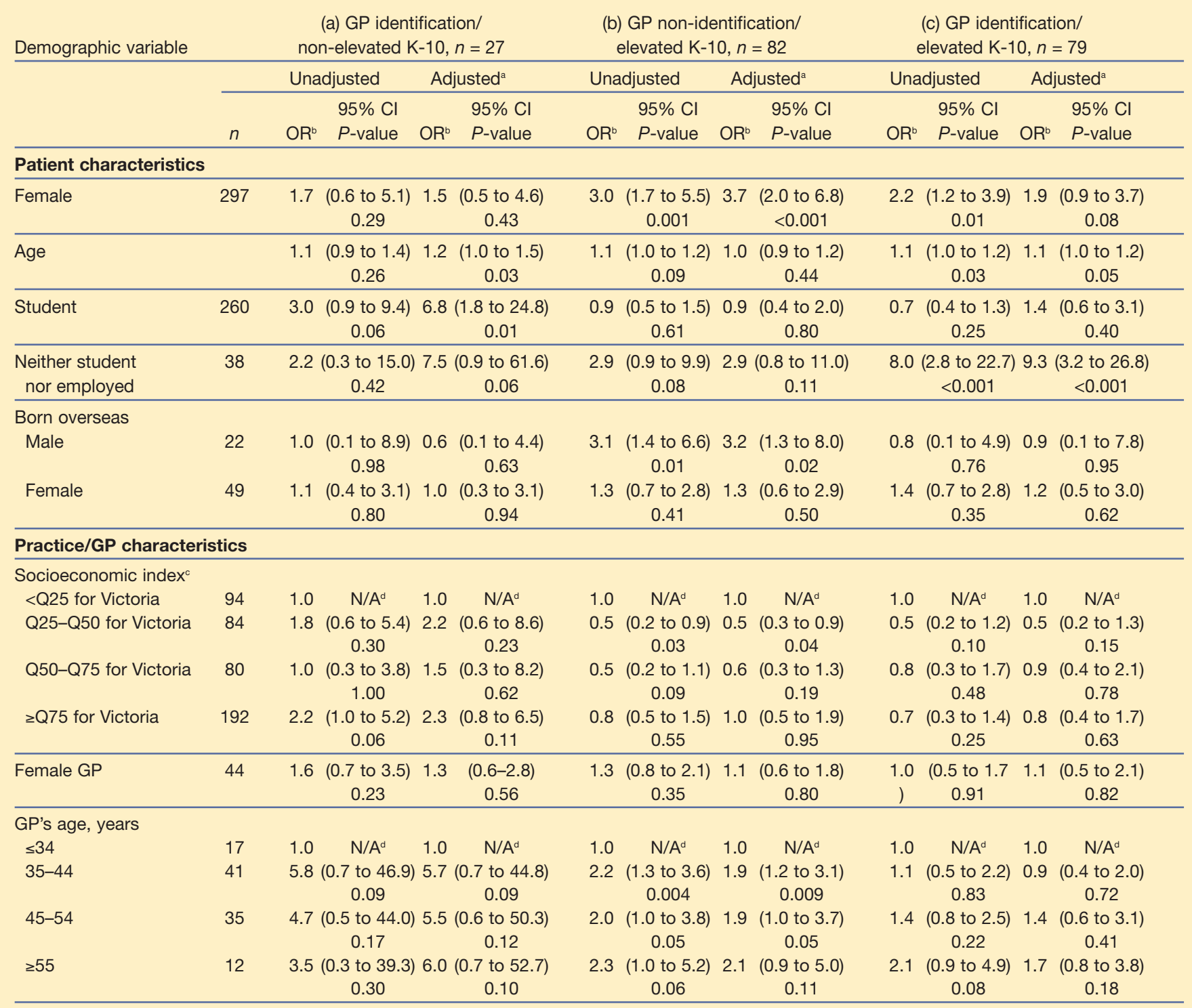

${ }^{a}$ Adjusted for the other confounders. ${ }^{b}$ Reference category for all analyses: neither identified by GP nor having high level of emotional distress on the K10. Index for the practice in which the participant was recruited. ${ }^{\circ}$ Baseline odds ratio. Note: since sex and place of birth interact in their effect on the outcome, the effect of being born overseas is presented separately for each sex. 


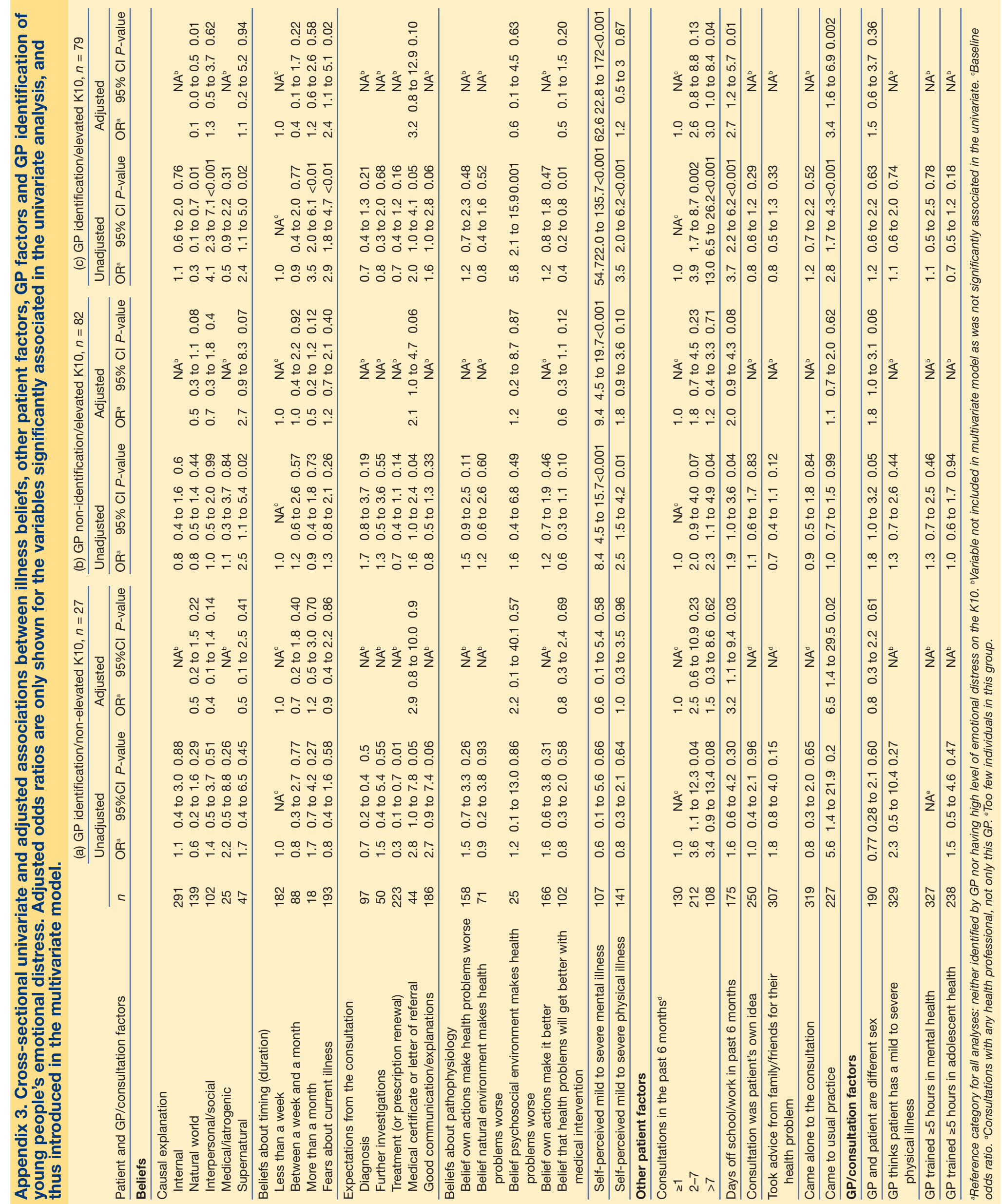

